\title{
Microstructure and Hydrophobic Properties of Nano-Cu-Coated Wood-Based Composites by Ultrasonic Pretreatment
}

\author{
Hongbo Mu ${ }^{1}$, Yanan Wang ${ }^{1}$, Yongqi Tian ${ }^{1}$, Xiaoming Duan ${ }^{2}{ }^{-}$, Jingkui Li ${ }^{1, *}$ and Dawei Qi ${ }^{1, *}$ \\ 1 College of Science, Northeast Forestry University, Harbin 150040, China; mhb506@nefu.edu.cn (H.M.); \\ wang_ya_nan@nefu.edu.cn (Y.W.); tian_yong_qi@nefu.edu.cn (Y.T.) \\ 2 School of Astronautics, Harbin Institute of Technology, Harbin 150001, China; xmduan@hit.edu.cn \\ * Correspondence: li_jing_kui@nefu.edu.cn, (J.L.); qidw9806@nefu.edu.cn (D.Q.)
}

Received: 25 June 2020; Accepted: 4 August 2020; Published: 6 August 2020

\begin{abstract}
The combination of nano-metal and wood to prepare copper-coated wood-based composite materials has important research value and practical significance for improving the function of wood, expanding the application field of wood, and adding added value. In this paper, 31-year-old wood (Pinus sylvestris L. var. mongholica Litv) veneer was taken as the research object. The wood veneer was pretreated by ultrasonic wave, and copper film was deposited on the surface of the wood veneer by magnetron sputtering to prepare "environmentally friendly" copper-plated wood-based composite materials. The microstructure and hydrophobic properties of Cu-coated wood-based composites were characterized and studied. With the increase in coating time, the diffraction peak intensity of wood cellulose gradually decreased, and the diffraction peaks of $\mathrm{Cu}(111), \mathrm{Cu}(200)$, and $\mathrm{Cu}(220)$ of metallic copper appeared. Under the sputtering condition of a substrate temperature of $200^{\circ} \mathrm{C}$, the copper film deposit on the surface of the wood was uniform and densely arranged. The surface water contact angle reached $149.9^{\circ}$. Ultrasonic treatment increases the porous structure of wood, and the rough metal copper film interface was constructed on the surface of wood by magnetron sputtering to transform the surface wettability of the wood from hydrophilic to super-hydrophobic. The lotus leaf effect was realized on the wood surface.
\end{abstract}

Keywords: wood base; microstructure; magnetron sputtering; ultrasonic pretreatment; hydrophobic properties

\section{Introduction}

Wood is a natural polymer material. Its main components are cellulose, hemicellulose, and lignin. The three major polymer materials (lignin, cellulose, and hemicellulose) are mutually interlaced, and a skeleton structure with porous channels is formed [1]. Cellulose and hemicellulose are carbohydrates, and lignin is a phenolic substance, all of which contain a large number of hydroxyl groups. Hydroxyl belongs to a hydrophilic group, which causes wood to absorb water molecules in the surrounding air until the water molecules in the wood and the water molecules in the air reach water balance [2]. Therefore, the conversion of wood from hydrophilic to hydrophobic is always associated with the covering, modification, or removal of hydroxyl groups. The porous structure of the surface of the wood and the existence of a large amount of hydroxyl groups can provide nucleation and film-forming substrates for inorganic nano particles and also provide the necessary conditions for the formation of hydrophobic film on the surface of wood [1]. Effectively improving the hydrophobic properties of wood is the basis for improving other properties of wood, such as bacteriostasis, conductivity, and electromagnetic shielding. The characteristic by which copper can 
maintain a stable structure during application can compensate for the shortcomings of wood, and it also has good electrical conductivity, ductility, and other advantages. The lotus leaf is renowned for its ability to shed water due to its multi-leveled roughness. The microstructure of lotus leaf showed that the unique wetting behavior was caused by the layered rough structure [3-5]. According to the lotus leaf effect, scholars generally believe that the super-hydrophobic surface is achieved by the combination of high surface roughness and hydrophobic materials [6-11]. The super-hydrophobic bionic functional surface based on the lotus effect has been applied in coatings, films, fibers, and other macroscopic fields and has shown great application value.

In recent years, there have been a large number of studies on various aspects of ultrasonic treatment, and research on the preparation of metal coatings and composite materials by ultrasonic-assisted chemical method has become more extensive [12-14]. Ultrasonic-assisted treatment of wood has a great influence on the physics and chemistry of wood [15]. Research found that ultrasonic cavitation can disperse the dirt attached to the surface of the material and the dead corners, enhancing the cleaning effect on the surface and inside the veneer [14]. The effect of ultrasonic treatment on the porosity of polymer foams is studied by Torres-Sanchez $\mathrm{C}$. The setting of ultrasonic parameters (frequency and power) has a direct impact on the size and distribution of the pores of polymer foams. The pore size and distribution are proportional to the power and frequency of ultrasonic signals. Ultrasound provides an entirely new way to increase porosity by controlling the frequency and power of the ultrasonic waves to achieve the desired porosity [16]. Zhao Guangjie et al. used ultrasound to treat wood veneer and study the changes in wood structure and crystallinity after ultrasound treatment [17].

Magnetron sputtering is a kind of physical vapor deposition which can be used to prepare various thin film materials such as metal, semiconductors, insulators, etc. It has the advantages of simple equipment, easy control, large coating area and strong adhesion, and no pollution such as waste gas and wastewater. When magnetron sputtering works, electrons collide with argon atoms in the process of flying to the substrate under the action of electric field. Ar ions accelerate to the cathode target under the action of electric field and bombard the surface of the target with high energy, causing the target to sputter. Green production technology that meets environmental standards has been widely used in the preparation of various nanomaterial films in recent years [18,19]. In the previous study, a chemical sealing agent was used to treat the surface of wood veneer, and metallization of wood veneer was achieved by magnetron sputtering [20]. Therefore, this was due to the fact that there are many dust particles and impurities on the surface, and it is difficult to form a metal film on the surface of the wood without treating the wood with any chemical sealing agent. The use of physical methods to achieve the preparation of "environmentally friendly" wood-based nano-metal composite materials has always been our direction. At present, Li Jingkui and others have tried to use physical methods to prepare copper films with good mechanical properties on the surface of wood veneer, but there are still many areas that need to be improved [21]. In this paper, the wood (Pinus sylvestris L. var. mongholica Litv) veneer without any chemical treatment was used as the substrate, and the copper film was deposited on the surface of the ultrasonic pretreated wood veneer by magnetron sputtering to prepare "environmentally friendly" nano-copper-coated wood-based composite materials. The microstructure and hydrophobic properties of $\mathrm{Cu}$-coated wood-based composites were characterized and studied.

\section{Materials and Methods}

\subsection{Test Materials}

The 31-year-old Pinus sylvestris L. var. mongholica Litv veneer was used as the experimental material, and the heart wood was selected. The veneer size was about $15 \mathrm{~mm}((\mathrm{~L})) \times 15 \mathrm{~mm}((\mathrm{~T})) \times 0.5 \mathrm{~mm}((\mathrm{R}))$. Other materials: purity of $99.99 \%$ copper target, absolute ethanol, dilution formic acid, acetone, distilled water, and sandpaper. 


\subsection{Ultrasound Pretreatment of Wood Veneer}

The wood veneer samples were polished through metallographic sandpaper from 600 to 2000 mesh, and the wood chips on the surface were dried with a blower. Ultrasound treatment of wood veneers with alcohol could create conditions for the deposition of copper film on the wood surface. First, we added half of the total volume of distilled water to the ultrasonic cleaner, put the wood veneer into a beaker containing alcohol, and then put the beaker into an ultrasonic cleaner. Next, the beaker was placed in an ultrasonic cleaner with a power setting of $80 \mathrm{~W}$ and an ultrasonic time of $60 \mathrm{~min}$. Finally, we removed it with tweezers and air-dried it. The ultrasonic pretreatment of wood veneer is shown in Figure 1.

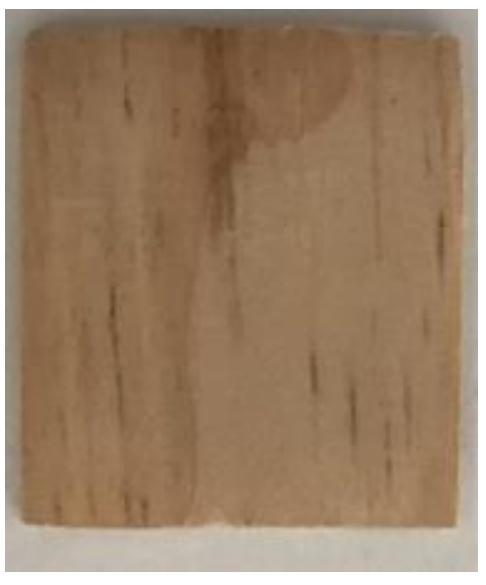

(a) Before treatment

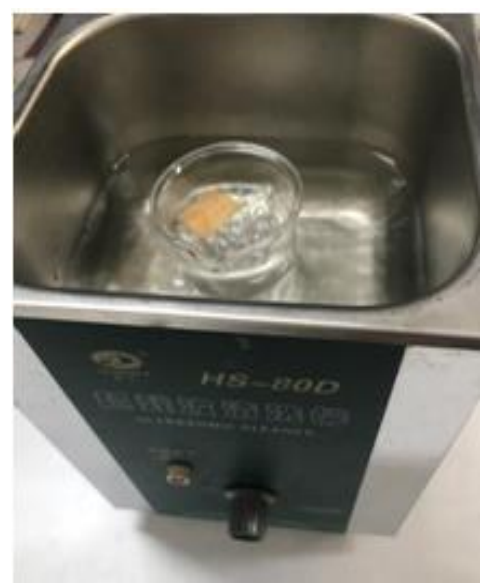

(b) Processing

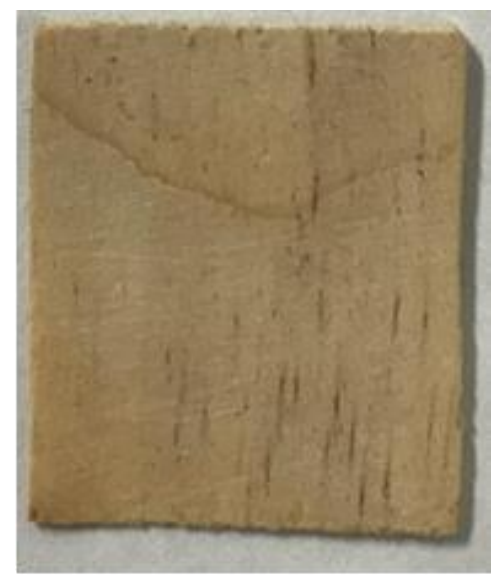

(c) After processing

Figure 1. Ultrasonic pretreatment of wood veneer.

\subsection{Preparation of "Environmentally Friendly" Copper-Plated Wood-Based Composite Materials}

The preparation of "environmentally friendly" copper-plated wood-based composite materials was carried out on a JGP450 multi-target magnetron sputtering equipment. The schematic diagram of magnetron sputtering copper plating is shown in Figure 2. The sputtering target was a copper target (purity of 99.99\%), and the copper film on the surface of the wood was prepared by direct current (DC) sputtering. The substrate was wood veneer pretreated by ultrasound. The specific magnetron sputtering conditions and process parameters are set out in Table 1.

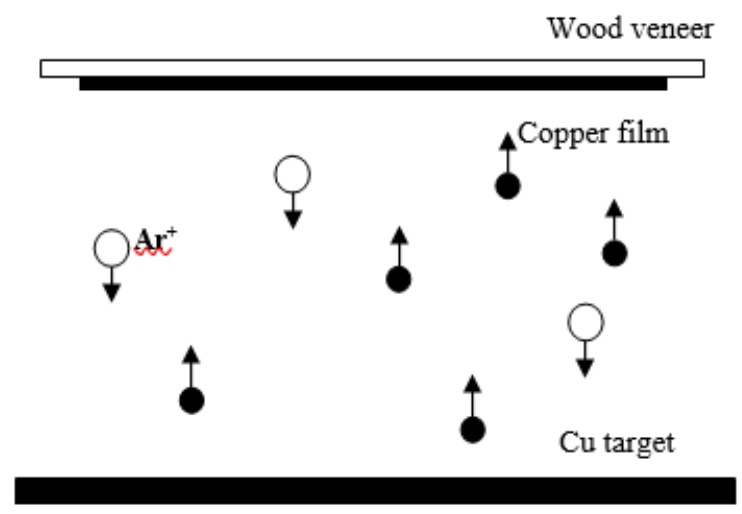

Figure 2. Schematic diagram of magnetron sputtering copper plating. 
Table 1. Magnetron sputtering conditions and parameter settings.

\begin{tabular}{ccccccc}
\hline Number & $\begin{array}{c}\text { Ultrasonic } \\
\text { Processing } \\
\text { Time/Min }\end{array}$ & $\begin{array}{c}\text { Sputtering } \\
\text { Time }\end{array}$ & $\begin{array}{c}\text { Substrate } \\
\text { Temperature }\end{array}$ & $\begin{array}{c}\text { Sputtering } \\
\text { Power/W }\end{array}$ & $\begin{array}{c}\text { Sputtering } \\
\text { Pressure/Pa }\end{array}$ & $\begin{array}{c}\text { Film } \\
\text { Thickness/nm }\end{array}$ \\
\hline $\mathrm{a}$ & 0 & $0 \mathrm{~s}$ & Room temperature & - & - & - \\
$\mathrm{b}$ & 60 & $50 \mathrm{~s}$ & Room temperature & 75 & 5.0 & - \\
$\mathrm{c}$ & 60 & $150 \mathrm{~s}$ & Room temperature & 75 & 5.0 & 13 \\
$\mathrm{~d}$ & 60 & $10 \mathrm{~min}$ & Room temperature & 75 & 5.0 & 57 \\
$\mathrm{e}$ & 60 & $15 \mathrm{~min}$ & Room temperature & 75 & 5.0 & 141 \\
$\mathrm{f}$ & 60 & $15 \mathrm{~min}$ & $200^{\circ} \mathrm{C}$ & 75 & 5.0 & 105 \\
\hline
\end{tabular}

\subsection{Structural Characterization of "Environmentally Friendly" Copper-Plated Wood-Based} Composite Materials

The XRD-6100 produced by Shimadzu Corporation of Japan was used to characterize the structure of "environmentally friendly" nano-metal wood-based composite materials under the conditions of $\mathrm{CuK} \alpha$ copper target radiation $(\lambda=0.154 \mathrm{~nm})$, with a radiant tube voltage of $40 \mathrm{kV}$, radiant tube current of $30 \mathrm{~mA}$ and scanning range of 10 80 degrees. The test analysis uses Bragg-Brentano geometry. The film sample had a fixed tilt angle of $4^{\circ}$, steps of $0.02^{\circ}$ and a scanning speed of $2^{\circ}$ per min The crystallinity of wood was measured by the crystallinity index. It was calculated from the percentage of the whole sample constituted by the crystalline part. The change in the crystallinity of wood cellulose was calculated by the empirical method of Segal et al [22-24]. As shown in Formula (1), the relative crystallinity of wood cellulose is as follows:

$$
C_{r} I \%=\frac{I_{002}-I_{a m}}{I_{002}} \times 100 \%
$$

where $C_{r} I \%$ is the relative crystallinity, $I_{002}$ is the maximum intensity of the (002) lattice diffraction angle (near $22^{\circ}$ ), and $I_{a m}$ is the diffraction intensity of the amorphous region (near $18^{\circ}$ ).

\subsection{Micro-Morphology and Wettability Test of "Environmentally Friendly" Copper-Plated Wood-Based Composite Materials}

The wettability of "environmentally friendly" wood-based nano-metal composite materials was tested by DSA-100S contact angle measuring instrument produced by Kruss. Using the static droplet method, the test liquid was distilled water, and the volume of droplets was $7 \mu \mathrm{L}$. Each sample was randomly selected from three different positions on the surface of the sample, a single photographing test was completed in $5 \mathrm{~s}$, and the average value was taken and recorded. The change in functional groups on the surface of metallized wood was analyzed by 1iS10 Fourier transform infrared spectroscopy (FTIR) of Thermo Fisher Scientific, Inc. The instrument was equipped with a multi-functional attenuated total reflection (ATR) sampling accessory, Deuterated triglycine sulfate detector (DTGS), and diamond crystal. The infrared scanning range was 500 to $4000 \mathrm{~cm}^{-1}$, resolution was $4 \mathrm{~cm}^{-1}, 32$ scans were performed for each sample, and automatic air suppression was set to deduct the influence of absorption peaks caused by carbon dioxide and water in the air. The morphology of wood veneer metallization was characterized by JSM-7500F cold field emission scanning electron microscopy (SEM), and the surface elements of the wood-based nano-metal composite materials were analyzed by Oxford X-Max refrigeration energy spectrometer (EDS). The acceleration voltage of EDS is $15 \mathrm{KV}$.

\section{Results and Analysis}

\subsection{Effect of Different Treatments on Crystallization Properties of Wood}

\subsubsection{Effect of Ultrasonic Pretreatment on the Crystallization Properties of Wood}

The structure change of wood cellulose after ultrasonic pretreatment is shown in Figure 3. It could be seen from the XRD pattern that, after the ultrasonic treatment of the wood veneer, there are still 
characteristic peaks of three crystal faces $(101,002$, and 040$)$ of cellulose in the wood at $2 \theta$, equal to $17.0^{\circ}$, $22.3^{\circ}$, and $35.0^{\circ}$. The crystal structure of wood cellulose is not damaged, but the ultrasonic treatment of water will cause the diffraction peak intensity of wood cellulose to decrease, while the ultrasonic treatment of alcohol will cause the diffraction peak intensity of wood cellulose to increase. In the process of ultrasonic treatment of wood veneer, the shock wave with huge energy generated by the ultrasonic cavitation effect continuously impacted the amorphous deposits and gum in the pore of the wood veneer. Although the internal extracts and ash of the wood are removed, some cells on the surface of the wood are also destroyed, resulting in a more disordered arrangement of cellulose microfibrils in the non-crystalline area. This is the reason for the decrease in the intensity and crystallinity of the wood diffraction peak caused by water-ultrasonic wood veneer (Figure 3a). Alcohol promotes the surface activity of cellulose microfibrils in the amorphous region, thereby generating hydroxyl groups, which promotes the order of microfibrils in the amorphous region and improves the intensity of the diffraction peak and the crystallinity of cellulose $[1,2,7]$. It could be seen that the combined treatment of alcohol and ultrasound can increase the diffraction peaks and relative wood cellulose crystallinity, which is caused by the dominant treatment of alcohol in the combined treatment (Figure 3b-f).

\subsubsection{Effect of Wood Veneer Metallization on Crystallization Properties of Wood}

The effect of wood veneer metallization on the crystallization properties of structural wood is shown in Figure 3. The relative intensity of the diffraction peak on the crystalline surface (002) decreases by $11.2 \%$ when coating time is $50 \mathrm{~s}, 6.3 \%$ when coating time is $150 \mathrm{~s}, 13.3 \%$ when coating time is $10 \mathrm{~min}$, and $19.8 \%$ when coating time is $15 \mathrm{~min}$. Additionally, the intensity of the diffraction peak of the sample at $15 \mathrm{~min}\left(200^{\circ} \mathrm{C}\right)$ decreased by $25.5 \%$. One of the reasons for the decrease in diffraction peak intensity is that the thickness of copper film increases and the depth of $X$-ray radiation in wood decreases with the increase in coating time. Another reason is that the deposited copper film absorbs and reflects the diffraction line of wood, which also causes the peak intensity of wood cellulose to decrease [25]. The relative crystallinity of wood cellulose is calculated according to the formula of crystallinity in Formula (1). The crystallinity changes of different treatment methods are shown in Table 2. Comparing the sample after copper plating with the sample before copper plating (ethanol ultrasonic treatment), the crystallinity of the sample after copper plating hardly changed, and the change rule is not obvious. The cellulose molecular chains in the wood crystalline region are orderly arranged, and the sputtered copper atoms cannot enter the crystallization region. However, although the structure of the amorphous region is loose, ultrasonic treatment of the wood veneer will cause alcohol molecules to occupy the voids of the wood in the amorphous region, stimulating the surface activity of cellulose microfibrils in the amorphous region. The resulting hydroxyl group makes the microfibrils in the amorphous region tend to be ordered. In group e of Table 2, since the density of this group of wood samples may be uneven at different locations, ultrasonic treatment has a lesser effect on locations with higher density. The difference in the content and structure of the wood itself will also lead to different degrees of crystallinity [26]. Although the crystallinity of the wood treated by ultrasonic has little change, it will increase the permeability of the wood $[17,27,28]$. During the coating process, the sputtered copper atoms only partially enter the voids on the surface of the wood and penetrate into the amorphous region of the wood cell wall, which has little effect on the crystallinity of the wood cellulose [15,17]. 


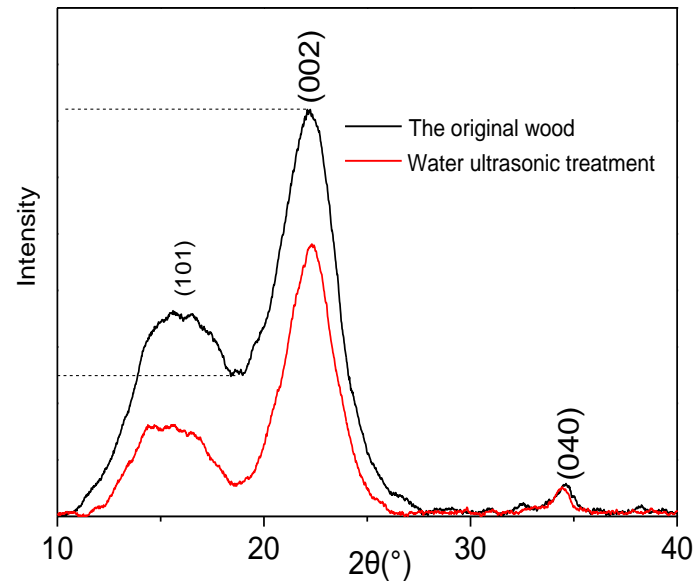

(a)

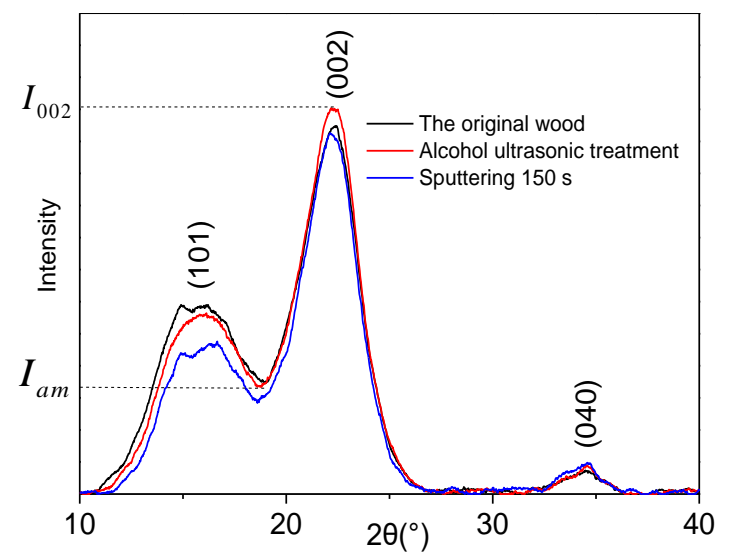

(c)

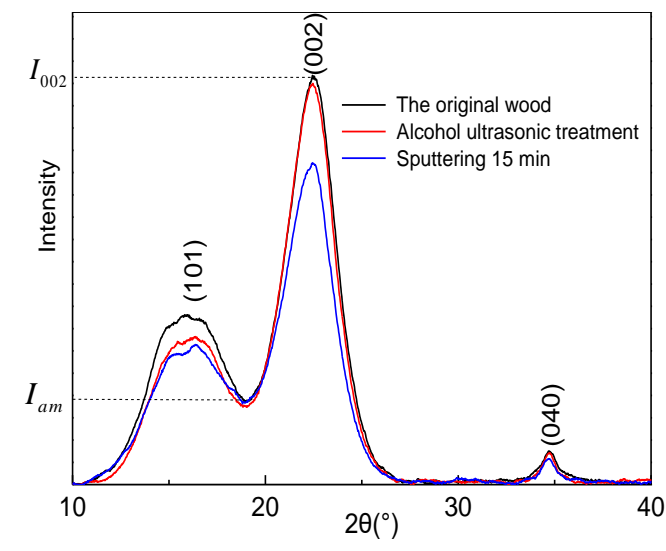

(e)

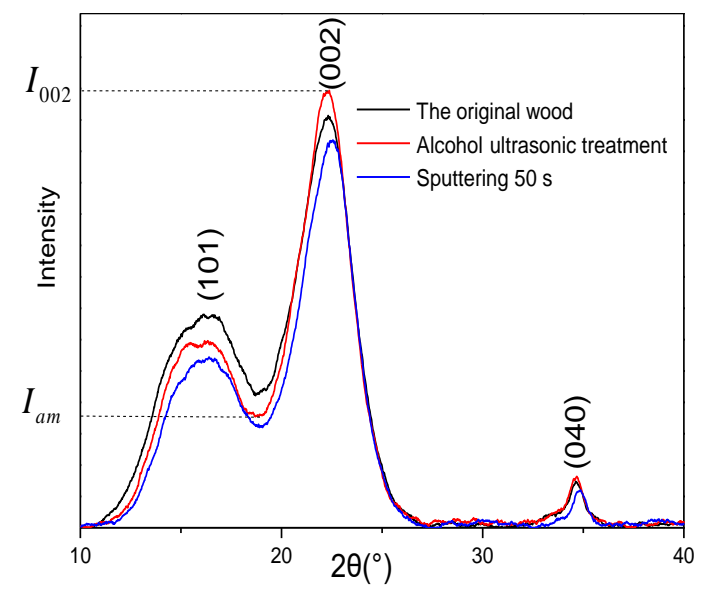

(b)

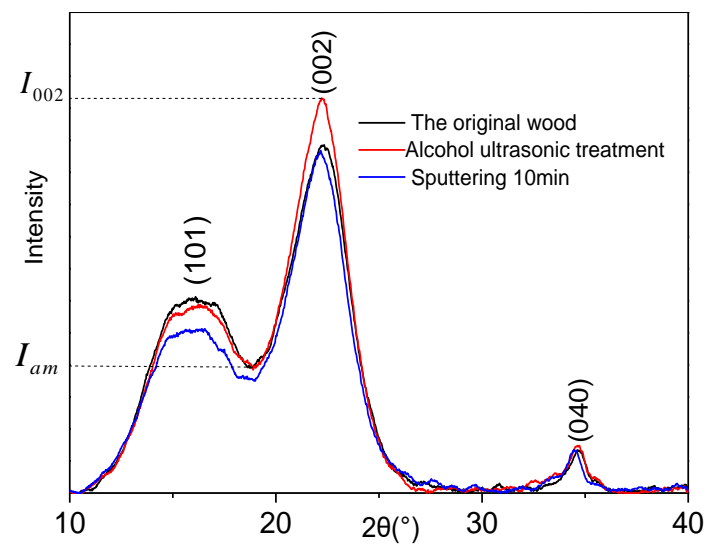

(d)

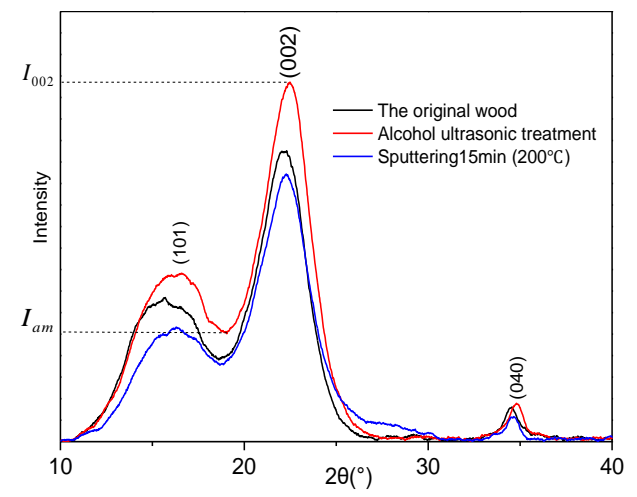

(f)

Figure 3. XRD map of wood veneer under different treatments in the range of $10^{\circ}$ to $40^{\circ}$, (a) Ultrasonic treatment with water; (b) Magnetron sputtering for $50 \mathrm{~s}$; (c) Magnetron sputtering for $150 \mathrm{~s}$; (d) Magnetron sputtering for $10 \mathrm{~min}$; (e) Magnetron sputtering for $15 \mathrm{~min}$; (f) Magnetron sputtering for $15 \min \left(200^{\circ} \mathrm{C}\right)$.

\subsection{Copper Film Structure on the Surface of Wood Veneer}

The XRD pattern of the copper film on the wood surface is shown in Figure 4. The diffraction peaks of $\mathrm{Cu}(111), \mathrm{Cu}(200)$, and $\mathrm{Cu}(220)$ appeared gradually around $2 \theta$, equal to $43.3^{\circ}, 50.4^{\circ}$, and $74.1^{\circ}$, and the intensity of the diffraction peaks gradually increased with the increase in sputtering time. 
When the sputtering time is $50 \mathrm{~s}$, there was no obvious characteristic diffraction peak of copper, which indicated that the copper film is in a microcrystalline or amorphous state. When the sputtering time is $150 \mathrm{~s}$, the $\mathrm{Cu}(111)$ diffraction peak appears. When the sputtering time is 15 minutes, the diffraction peaks of $\mathrm{Cu}$ (111), $\mathrm{Cu}(200)$, and $\mathrm{Cu}(220)$ appear. The characteristic diffraction peak intensity of copper is higher, and the shape of the diffraction peak is sharper, which reflects a good crystallization state. With the increase in sputtering copper plating time, the characteristic diffraction peak intensity of copper is gradually enhanced, and the intensity of the $\mathrm{Cu}(111)$ crystal face diffraction peak is the most obvious. The copper film deposition on the surface of wood has the preferred orientation of the $\mathrm{Cu}(111)$ crystal face. Since the structure of metallic copper belongs to the face-centered cubic lattice structure, in the three crystal faces of the copper film, the $\mathrm{Cu}(111)$ crystal face has a large atomic areal density, and the surface energy of the crystal face is relatively small, which is beneficial to $\mathrm{Cu}$ (111) crystal face growth.

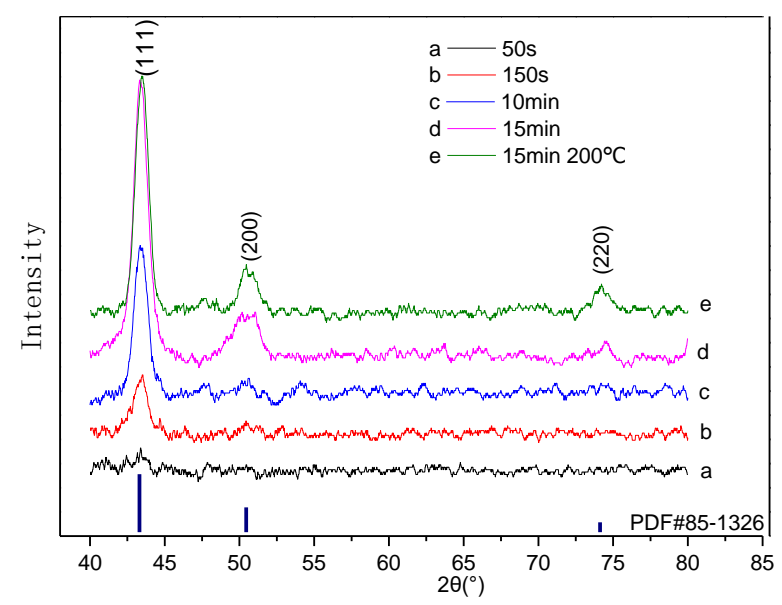

Figure 4. XRD map of wood veneer under different treatments in the range of $40^{\circ}$ to $80^{\circ}$.

Table 2. Crystallinity of samples after different treatment.

\begin{tabular}{|c|c|c|c|}
\hline Number & $\begin{array}{c}\text { Different Processing } \\
\text { Methods }\end{array}$ & $\begin{array}{l}\text { Cellulose Relative } \\
\text { Crystallinity }\end{array}$ & $\begin{array}{c}\text { Standard Deviation of } \\
\text { Crystallinity }\end{array}$ \\
\hline \multirow{3}{*}{ a } & Ultrasonic treated wood & $74.4 \%$ & $0.543 \%$ \\
\hline & The original wood & $67.9 \%$ & $0.666 \%$ \\
\hline & Sputtering for $50 \mathrm{~s}$ & $74.1 \%$ & $0.743 \%$ \\
\hline \multirow{3}{*}{$\mathrm{b}$} & Ultrasonic treated wood & $72.2 \%$ & $0.333 \%$ \\
\hline & The original wood & $69.5 \%$ & $0.447 \%$ \\
\hline & Sputtering for $150 \mathrm{~s}$ & $74.8 \%$ & $0.438 \%$ \\
\hline \multirow{3}{*}{ c } & Ultrasonic treated wood & $68.3 \%$ & $0.537 \%$ \\
\hline & The original wood & $63.8 \%$ & $0.486 \%$ \\
\hline & Sputtering for $10 \mathrm{~min}$ & $67.2 \%$ & $0.876 \%$ \\
\hline \multirow{3}{*}{$\mathrm{d}$} & Ultrasonic treated wood & $80.6 \%$ & $0.810 \%$ \\
\hline & The original wood & $79.7 \%$ & $0.743 \%$ \\
\hline & Sputtering for $15 \mathrm{~min}$ & $74.8 \%$ & $0.857 \%$ \\
\hline \multirow{3}{*}{$\mathrm{e}$} & Ultrasonic treated wood & $69.9 \%$ & $0.600 \%$ \\
\hline & The original wood & $71.9 \%$ & $1.057 \%$ \\
\hline & $\begin{array}{l}\text { Sputtering for } 15 \mathrm{~min} \\
\left(200^{\circ} \mathrm{C}\right)\end{array}$ & $71.4 \%$ & $0.982 \%$ \\
\hline
\end{tabular}

\subsection{Wetting Properties of "Environmentally Friendly" Copper-Plated Wood-Based Composite Materials}

The surface wettability of the wood veneer is represented by the contact angle of the liquid on its surface. The larger the contact angle, the lower the surface wettability. When the surface static contact 
angle is greater than $90^{\circ}$, it indicates that the surface of the test piece is a hydrophobic surface and the opposite indicates a hydrophilic surface [29]. The water contact angle of the "environmentally friendly" wood-based nano-metal composite material is shown in Figure 5. The contact angle of the untreated original wood is $53.5^{\circ}$ - that is, water can partially wet the original wood, which indicates that the porous structure of wood itself and the large number of polar functional groups on the surface of wood can attract and combine with water droplets, thus showing certain wettability. When the sputtering time is $50 \mathrm{~s}$, the water contact angle is $130.6^{\circ}$. When the sputtering time is $150 \mathrm{~s}$, the contact angle is $135^{\circ}$. The water contact angle of samples with magnetron sputtering times of $10 \mathrm{~min}$ and $15 \mathrm{~min}$ is over $145^{\circ}$. The contact angle of the sample with a sputtering time of $15 \mathrm{~min}\left(200^{\circ} \mathrm{C}\right)$ is $149.9^{\circ}$, which almost possesses superhydrophobic properties. Since the wood itself is a porous material and the structure is loose, the sputtered copper is directly filled into the pores of the wood, and copper film is formed on the surface of the wood to construct a hydrophobic system on the surface of the wood. In addition, the hydrophobicity of the material is related to the roughness of the surface of the material. The rougher the surface of hydrophobic materials, the better their hydrophobicity [30]. Table 3 shows the contact angle and standard deviation of the wood veneer surface before and after coating.

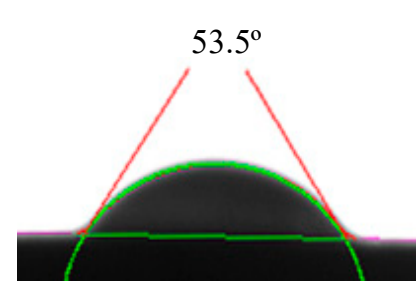

(a)

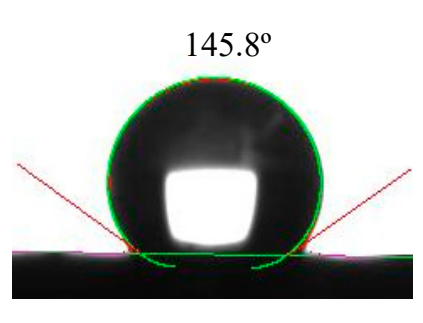

(d)

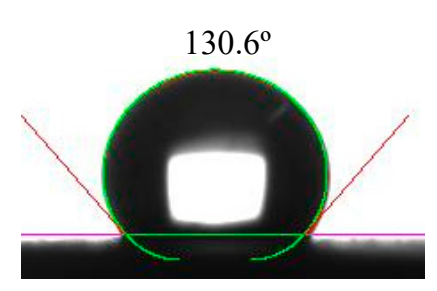

(b)

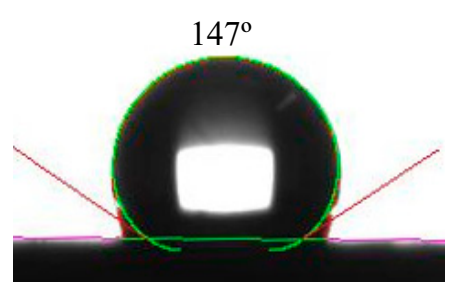

(e)

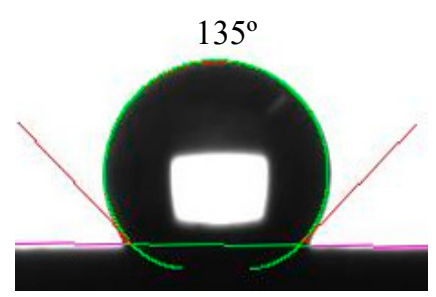

(c)

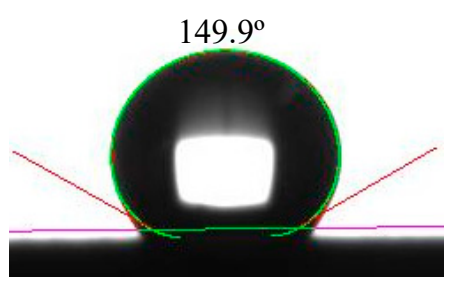

(f)

Figure 5. Water contact angle of copper-plated wood veneer, (a) is the original wood; (b) Magnetron sputtering for $50 \mathrm{~s}$; (c) Magnetron sputtering for $150 \mathrm{~s}$; (d) Magnetron sputtering for $10 \mathrm{~min}$; (e) Magnetron sputtering for $15 \mathrm{~min}$; (f) Magnetron sputtering for $15 \mathrm{~min}\left(200^{\circ} \mathrm{C}\right)$.

Table 3. Contact angle and standard deviation of surface of wood veneer before and after coating.

\begin{tabular}{cccc}
\hline Number & Sputtering Time & Contact Angle & Standard Deviation of Contact Angle \\
\hline $\mathrm{a}$ & $0 \mathrm{~s}$ & 53.5 & 0.985 \\
$\mathrm{~b}$ & $50 \mathrm{~s}$ & 130.6 & 0.656 \\
$\mathrm{c}$ & $150 \mathrm{~s}$ & 135 & 0.529 \\
$\mathrm{~d}$ & $10 \mathrm{~min}$ & 145.8 & 0.529 \\
$\mathrm{e}$ & $15 \mathrm{~min}$ & 147 & 0.346 \\
$\mathrm{f}$ & $15 \min \left(200^{\circ} \mathrm{C}\right)$ & 149.9 & 0.361 \\
\hline
\end{tabular}




\subsection{Infrared Spectrum Analysis}

Fourier transform infrared spectroscopy (FTIR) of "environmentally friendly" wood-based nano-metal composite materials is shown in Figure 6. Since the copper film itself has a strong absorption effect on infrared ray, the deposition of copper film on the wood surface will result in a significant reduction in the infrared absorption peak intensity of wood veneer [31]. In the FTIR spectrum of the original wood, the absorption peak around $3330 \mathrm{~cm}^{-1}$ is caused by the vibration of the surface hydroxyl (-OH) of the wood surface [32]. Compared with the FTIR spectrum of the original wood, depositing copper film on the surface of the wood veneer will result in a significant decrease in the absorption peak intensity of the hydroxyl groups of the wood veneer. Deposition of copper film on the surface of wood veneer resulted in a significant decrease in the hydroxyl absorption peak strength of the wood veneer, which is attributed to the deposition of copper film covering hydroxyl $(-\mathrm{OH})$ functional groups on the surface of the wood veneer. It can be seen that, as the sputtering time increases, the magnetron sputtering method deposits copper film on the surface of the wood to completely cover the surface of the wood veneer, resulting in a decrease in the absorption peak intensity.

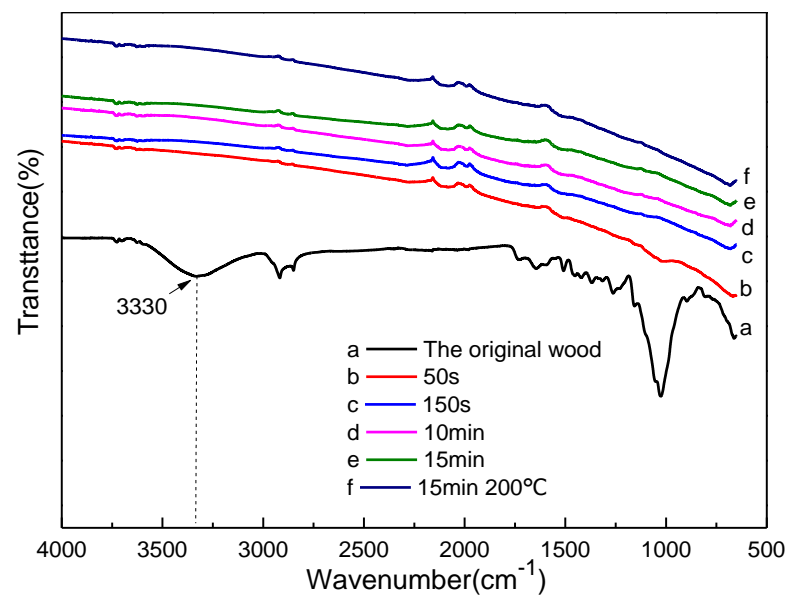

Figure 6. FTIR map of metallized wood veneer.

\subsection{Microscopic Morphology of Nano-Metal Wood-Based Composite Materials}

The scanning electron micrograph (SEM) of the wood-based nano-metal composite materials is shown in Figure 7. Ultrasonic waves continuously impact the amorphous deposits, gums, and fillers in the pores, and the extracts and ash in the pores of the wood were effectively removed. This makes the surface of the wood and the interior of the pores clean and smooth, creating conditions for sputter coating. After ultrasonic treatment, the fibers, pore, vessel, and parenchyma cells on the surface of the wood veneer are clearly visible (Figure 7a). The thickness of the copper film on the sample surface is shown in Table 1. For samples with a coating time of $50 \mathrm{~s}$, due to the short sputtering time, less copper is deposited on the surface of the wood, the wood pore size is still clearly visible, and the surface fibers of the wood are not covered. The film deposition is in the nucleation and accumulation stage, and no continuous film is formed (Figure $7 \mathrm{~b}$ ). The copper film deposited on the surface of the wood veneer with a coating time of $150 \mathrm{~s}$ has been nucleated and grown up in the small island stage, and a network structure film is formed. The sputtered copper atoms are basically filled with small pores, and most of the wood surface is covered by copper film (Figure 7c). The surfaces of the samples with coating times of $10 \mathrm{~min}$ and $15 \mathrm{~min}$ have been completely covered by the copper film. The film is more uniform and flat, but there are voids on the surface of the film (Figure $7 \mathrm{~d}, \mathrm{e}$ ). When the substrate temperature is $200{ }^{\circ} \mathrm{C}$, the formed copper film is uniform, dense, and flat, with fewer surface voids. It is almost connected as a whole. The surface of the wood forms a structure similar to a lotus leaf, and the overall shape looks smoother. A film with superior physical properties is obtained (Figure 7f). 


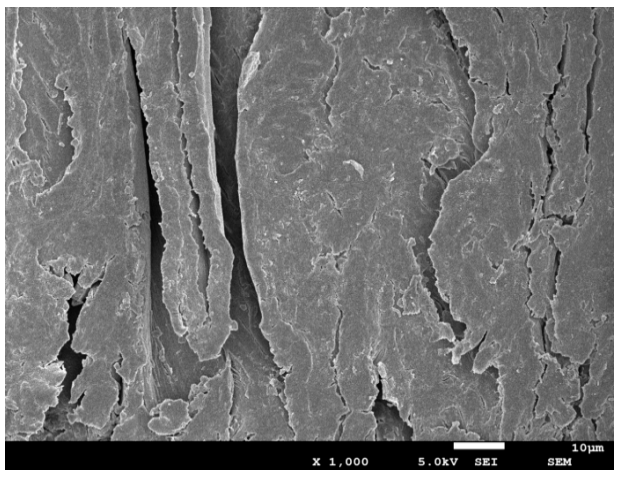

(a)

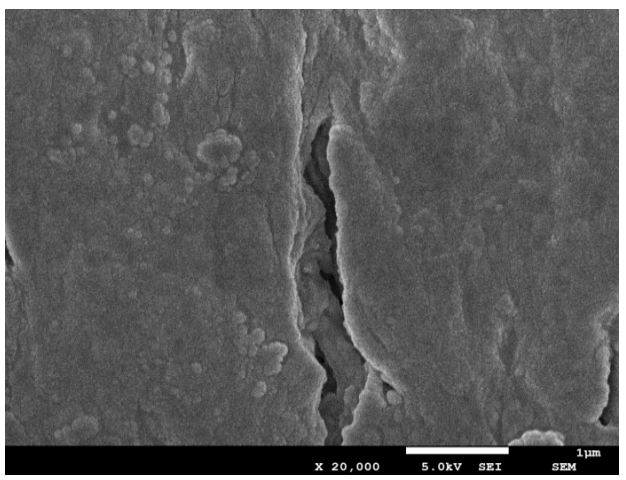

(c)

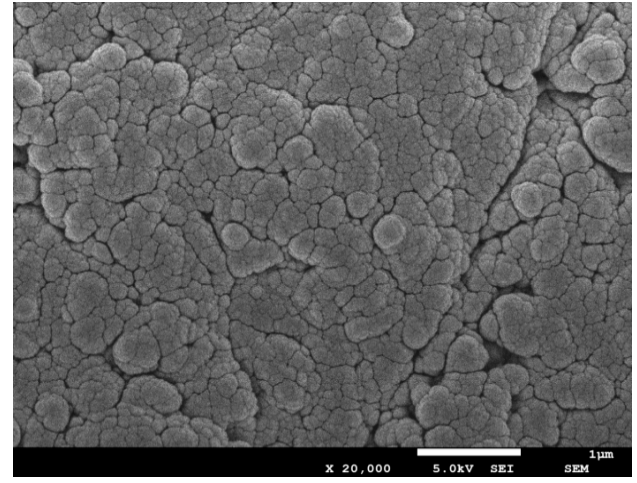

(e)

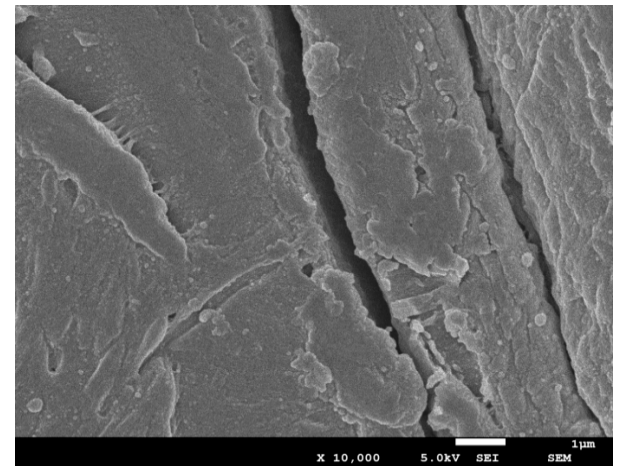

(b)

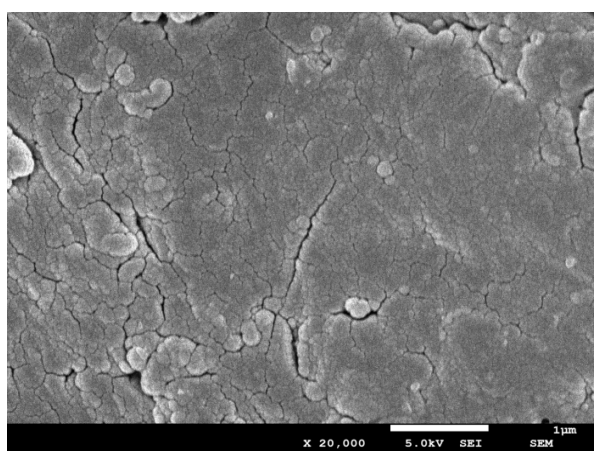

(d)

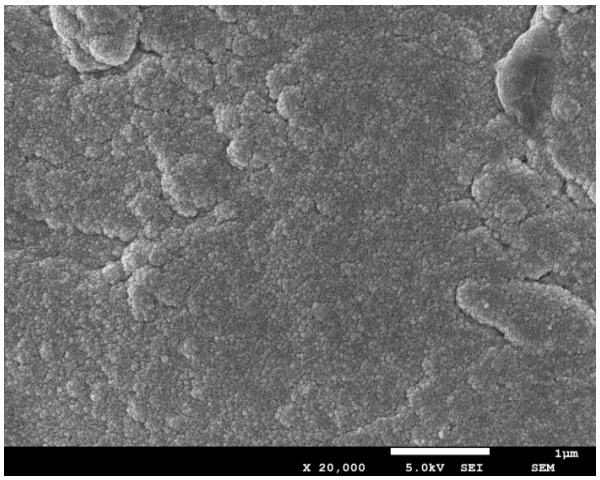

(f)

Figure 7. Metallized wood veneers scanning electron microscopy (SEM), (a) Ultrasonic treatment wood; (b) Magnetron sputtering for $50 \mathrm{~s}$; (c) Magnetron sputtering for $150 \mathrm{~s}$; (d) Magnetron sputtering for $10 \mathrm{~min}$; (e) Magnetron sputtering for $15 \mathrm{~min}$; (f) Magnetron sputtering for $15 \mathrm{~min}\left(200^{\circ} \mathrm{C}\right)$.

\subsection{Surface Element Analysis of Nano-Metal Wood-Based Composite Materials}

The EDS spectrum of the "environmentally friendly" metallized wood surface is shown in Figure 8. The weight percentage of surface elements before and after coating is shown in Table 4 . In the five groups of samples with magnetron sputtering times of $50 \mathrm{~s}, 150 \mathrm{~s}, 10 \mathrm{~min}, 15 \mathrm{~min}$, and $15 \mathrm{~min}\left(200^{\circ} \mathrm{C}\right)$, the weight percentage of $\mathrm{Cu}$-containing elements is $18.77 \%, 55.44 \%, 81.76 \%, 86.12 \%$, and $84.76 \%$, respectively; the weight percentages of the C-containing elements is $45.38 \%, 24.77 \%, 10.41 \%, 8.05 \%$, and $9.21 \%$, respectively; the weight percentages of the O-containing elements is $35.85 \%, 19.79 \%, 7.83 \%$, $5.83 \%$, and $6.03 \%$, respectively. It can be seen that, in the initial stage of magnetron sputtering, although the sputtering time was short, the copper deposited on the surface of the wood is less, but the $\mathrm{Cu}$ 
element with relatively high content can be detected, indicating that the copper film on the surface of the wood grows faster. With the increase in sputtering time, the thickness of the $\mathrm{Cu}$ film deposited on the surface of the wood veneer increased gradually. For samples coated with magnetron sputtering for more than 10 minutes, the relative content of Cu element is more than $80 \%$ and the surface of the wood veneer is almost completely covered by film. In addition, the relative content of elements detected on the surface of copper-plated wood veneers with different substrate temperatures has little difference during the same sputtering time.

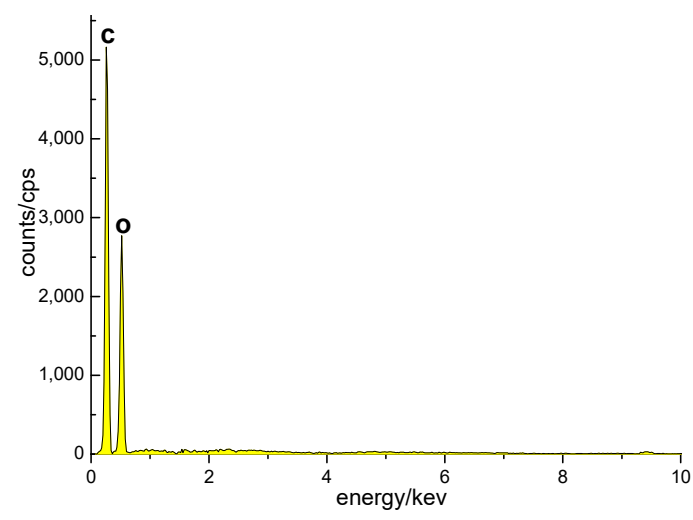

(a)

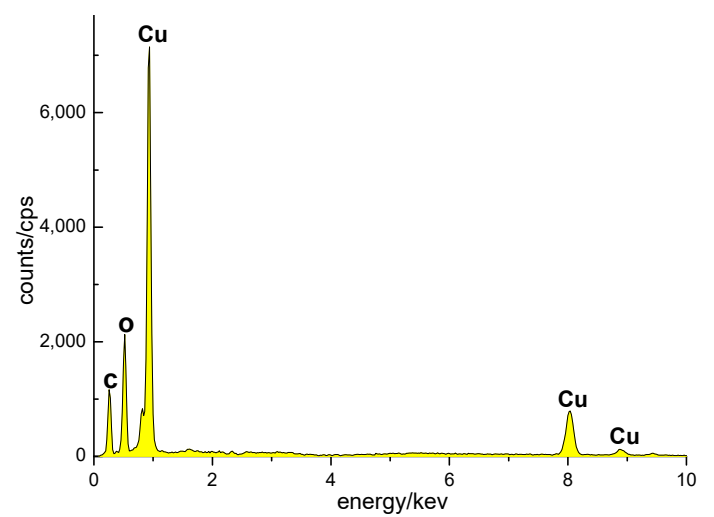

(c)

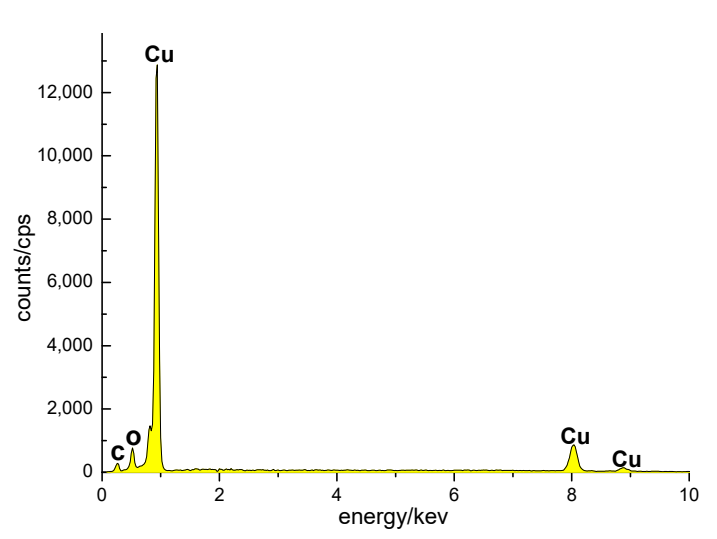

(e)

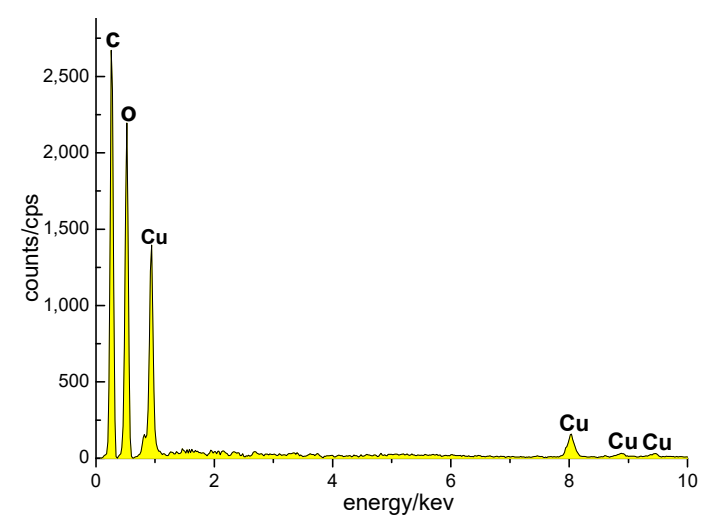

(b)

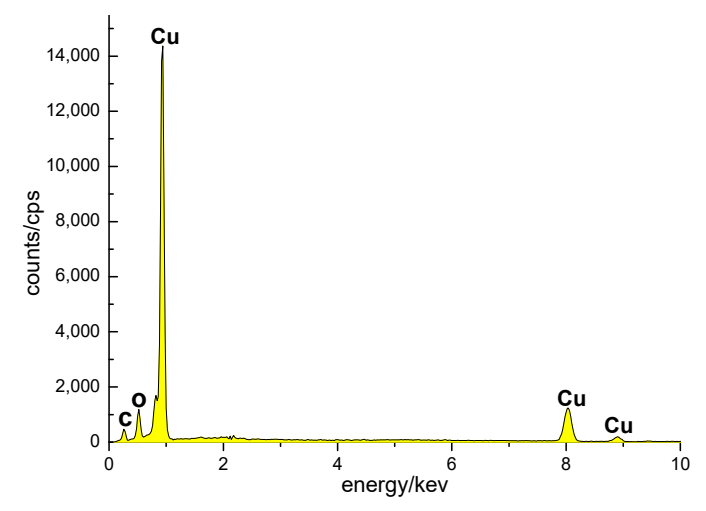

(d)

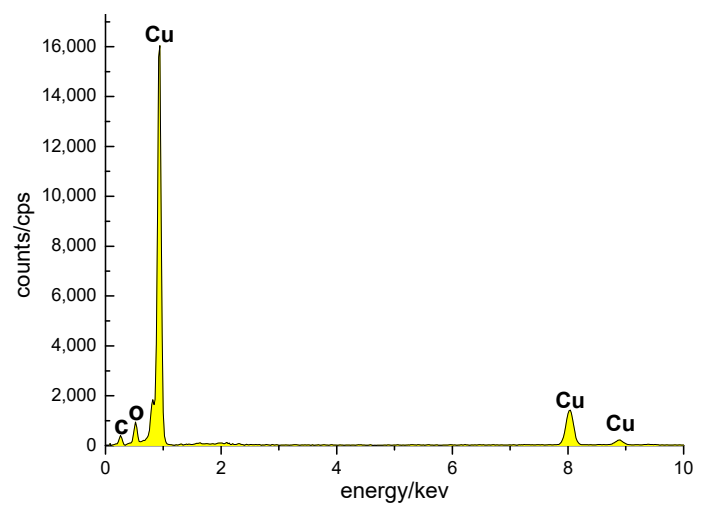

(f)

Figure 8. EDS map of copper-plated wood veneer, (a) Ultrasonic treatment wood; (b) Magnetron sputtering for $50 \mathrm{~s}$; (c) Magnetron sputtering for $150 \mathrm{~s}$; (d) Magnetron sputtering for $10 \mathrm{~min}$; (e) Magnetron sputtering for $15 \mathrm{~min}$; (f) Magnetron sputtering for $15 \mathrm{~min}\left(200^{\circ} \mathrm{C}\right)$. 
Table 4. Weight percentage of surface elements before and after coating.

\begin{tabular}{cccc}
\hline Sputtering Time & Element & Percentage by Weight/\% & Atom Percentage /\% \\
\hline \multirow{2}{*}{$0 \mathrm{~s}$} & $\mathrm{C}$ & 52.68 & 59.73 \\
& $\mathrm{O}$ & 47.32 & 40.27 \\
\hline \multirow{3}{*}{$50 \mathrm{~s}$} & $\mathrm{C}$ & 45.38 & 59.84 \\
& $\mathrm{O}$ & 35.85 & 35.49 \\
& $\mathrm{Cu}$ & 18.77 & 4.68 \\
\hline \multirow{3}{*}{$150 \mathrm{~s}$} & $\mathrm{C}$ & 24.77 & 49.43 \\
& $\mathrm{O}$ & 19.79 & 29.65 \\
& $\mathrm{Cu}$ & 55.44 & 20.92 \\
\hline \multirow{3}{*}{$10 \mathrm{~min}$} & $\mathrm{C}$ & 10.41 & 32.8 \\
& $\mathrm{O}$ & 7.83 & 18.51 \\
& $\mathrm{Cu}$ & 81.76 & 48.69 \\
\hline \multirow{3}{*}{$15 \mathrm{~min}$} & $\mathrm{C}$ & 8.05 & 28.03 \\
& $\mathrm{O}$ & 5.83 & 15.26 \\
& $\mathrm{Cu}$ & 86.12 & 56.71 \\
\hline \multirow{3}{*}{$15 \mathrm{~min}\left(200{ }^{\circ} \mathrm{C}\right)$} & $\mathrm{C}$ & 9.21 & 30.95 \\
& $\mathrm{O}$ & 6.03 & 15.21 \\
& $\mathrm{Cu}$ & 84.76 & 53.83 \\
\hline
\end{tabular}

\section{Conclusions}

In this paper, the Pinus sylvestris L. var. mongholica Litv veneers were used as the substrate, and the copper film was deposited on the surface of the ultrasonic pretreated wood veneer by magnetron sputtering to prepare the "environmentally friendly" copper-coated wood-based composite materials. The metallization of wood veneers does not affect the crystalline region of wood, and the crystal structure of wood cellulose is not destroyed, but the intensity of characteristic peaks of crystal faces is reduced. Ultrasonic treatment aggravates the porous structure of wood, and a rough metal copper film interface is constructed on the surface of the wood by magnetron sputtering to change the surface wettability of the wood from hydrophilic to strongly hydrophobic. Under the sputtering condition of a substrate temperature of $200^{\circ} \mathrm{C}$, the copper film is uniform, densely arranged, and the surface water contact angle reaches $149.9^{\circ}$, which has almost super-hydrophobic properties. It can be seen that ultrasonic treatment of wood aggravates the porous structure of wood and makes the surface of wood rougher. The magnetron sputtering method can be used to construct a rough metal film interface on the surface of the wood, so that the surface wettability of the wood undergoes a transformation from hydrophilic to strongly hydrophobic. The lotus leaf effect is realized on the wood surface. The ultrasonic treatment of wood combined with magnetron sputtering to prepare copper thin films can provide new ideas for wood modification. In future research, it can be combined with chemical methods to prepare more wood composites with strong practicality and excellent performance.

Author Contributions: Conceptualization, H.M. and J.L.; methodology, H.M.; software, J.L.; validation, H.M., J.L. and D.Q.; formal analysis, X.D.; investigation, Y.W.; resources, D.Q.; data curation, Y.T.; writing—original draft preparation, H.M.; writing-review and editing, J.L.; visualization, Y.W.; supervision, Y.W.; project administration, J.L.; funding acquisition, D.Q. All authors have read and agreed to the published version of the manuscript.

Funding: This work was supported by the Fundamental Research Funds for the Central Universities (2572020BC07).

Conflicts of Interest: The authors declare no conflict of interest.

Data Availability: The data that support the findings of this study are available within the article. The numerical datasets and additional SEM images are available from the corresponding author upon reasonable request. 


\section{References}

1. Wang, L.; Wang, Z.; Ning, G.Y.; Shen, Y.L.; Wang, X.M. Research Progress of Electromagnetic Shielding Wood-based Conductive Materials. Mater. Rev. 2018, 32, 2320-2328.

2. Wang, C.; Piao, C.; Lucas, C. Synthesis and Characterization of Superhydrophobic Wood Surfaces. J. Appl. Polym. Sci. 2011, 119, 1667-1672. [CrossRef]

3. Barthlott, W.; Neinhuis, C. Purity of the sacred lotus, or escape from contamination in biological Surfaces. Planta 1997, 202, 1-8. [CrossRef]

4. Darmanin, T.; Guittard, F. Superhydrophobic and superoleophobic properties in nature. Mater. Today 2015, 18, 273-285. [CrossRef]

5. Xu, P.; Coyle, T.W.; Pershin, L.; Mostaghimi, J. From lotus effect to petal effect: Tuning the water adhesion of non-wetting rare earth oxide coatings. J. Eur. Ceram. Soc. 2019, 40, 1692-1702. [CrossRef]

6. Cheng, Y.T.; Rodak, D.E.; Wong, C.A.; Hayden, C.A. Effects of Micro-and Nano-Structures on the Self-Cleaning Behaviour of Lotus Leaves. Nanotechnology 2006, 17, 1359. [CrossRef]

7. Wang, S.L.; Shi, J.Y.; Liu, C.; Xie, Y.C.; Wang, C.Y. Fabrication of a Superhydrophobic Surface on a Wood Substrate. Appl. Surf. Sci. 2011, 257, 9362-9365. [CrossRef]

8. Yin, B.; Fang, L.; Hu, J.; Tang, A.Q.; Wei, W.H.; He, J. Preparation and Properties of Super-hydrophobic Coating on Magnesium Alloy. Appl. Surf. Sci. 2010, 257, 1666-1671. [CrossRef]

9. Hui, T.S.; Tai, Y.; Yu, Q.C. Synthesis and Characterization of Carbon/Silica Superhydrophobic Multi-layer Films. Thin Solid Film. 2010, 518, 5183-5187.

10. Su, C.; Li, J. The Friction Property of Super-hydrophobic Cotton Textiles. Appl. Surf. Sci. 2010, 256, 4220-4225. [CrossRef]

11. Xing, Y.J.; Xue, Y.P.; Song, J.L.; Sun, Y.K.; Huang, L.; Liu, X.; Sun, J. Superhydrophobic Coatings on Wood Substrate for Self-Cleaning and EMI Shielding. Appl. Surf. Sci. 2018, 436, 865-872. [CrossRef]

12. Vitry, V.; Bonin, L. Effect of Temperature on Ultrasound-assisted Electroless Nickel-boron Plating. Ultrason. Sonochem. 2019, 56, 327-336. [CrossRef] [PubMed]

13. Arote, S.A.; Pathan, A.S.; Hase, Y.V.; Bardapurkar, P.P.; Gapale, D.L.; Palve, B.M. Investigations on Synthesis, Characterization and Humidity Sensing Properties of $\mathrm{ZnO}$ and $\mathrm{ZnO}-\mathrm{ZrO} 2$ Composite Nanoparticles Prepared by Ultrasonic Assisted Wet Chemical Method. Ultrason. Sonochem. 2019, 55, 313-321. [CrossRef]

14. Cai, A.H.; Thomas, L.J. Medical Diagnostic Ultrasound Contrastagent Destruction with Reduced Biological Effect. J. Acoust. Soc. Am. 2011, 130, 3180. [CrossRef]

15. Wang, Z.Y.; Qu, L.J.; Qian, J.; He, Z.B.; Yi, S.L. Effects of the ultrasound-assisted pretreatments using borax and sodium hydroxide on the physicochemical properties of chinese fir. Ultrason. Sonochem. 2019, 50, 200-207. [CrossRef]

16. Torres-Sanchez, C.; Corney, J.R. Effects of Ultrasound on Polymeric Foam Porosity. Ultrason. Sonochem. 2008, 15, 408-415. [CrossRef]

17. Xue, Z.H.; Zhao, G.J. Influence of Different Treatments of on Wood Crystal Properties. J. Northwest For. Univ. 2007, 22, 169-171.

18. Peng, J.; Chen, G.Q.; Song, Y.C.; Gu, K.M.; Tang, J.N. Study on Electrical Performance of Metal Copper Films Deposited by Magnetron Sputtering on Polyimide Flexible Substrates. Acta Phys. Sin. 2014, 63, 395-400.

19. Chang, D.L.; Qiu, T.Y.; Wang, Q.Y.; Huang, W.H.; Hu, W.H.; Zhang, Y.L.; Li, Y.Y. Experiment on Sputtering Metal Thin Film on Wood Surface. J. Northeast For. Univ. 2007, 35, 34-36.

20. Li, J.K.; Wang, R.Y.; Tian, H.; Wang, Y.N.; Qi, D.W. Research on the Gradual Process of the Metallization Structures and Mechanical Properties of Wood Veneer. Symmetry 2018, 10, 550. [CrossRef]

21. Li, J.K.; Wang, Y.N.; Zhang, J.C.; Qi, D.W. Physical Characteristics and Fluorescence Effect of "Environmentally friendly" Metallized Wood. AIP Adv. 2020, 10, 045133.

22. Segal, L.; Creely, J.J.; Martin, A.E.; Conrad, C.M. An Empirical Method for Estimating the Degree of Crystallinity of Native Cellulose using the X-ray Diffractometer. Text. Res. J. 1959, 29, 786-794. [CrossRef]

23. Mwaikambo, L.Y.; Ansell, M.P. Chemical Modification of Hemp, Sisal, Jute, and Kapok Fibers by Alkalization. J. Appl. Polym. Sci. 2002, 84, 2222-2234. [CrossRef]

24. Zhang, P.P.; Tong, D.S.; Lin, C.X.; Yang, H.M.; Zhong, Z.K.; Yu, W.H.; Wang, H.; Zhou, C.H. Effects of Acid Treatments on Bamboo Cellulose Nanocrystals. Asia Pac. J. Chem. Eng. 2015, 9, 686-695. [CrossRef] 
25. Xu, Y.; Wang, Z.S.; Xu, J.; Zhang, H.; Wang, H.C.; Zhu, J.T.; Wang, F.L.; Wang, B.; Qin, S.J.; Chen, L.Y. Characterization of Low-Z Material Layer Profiles in Bilayern Structures by X-ray Reflectivity Measurement. Opt. Precis. Eng. 2007, 15, 1838-1843.

26. Cheng, S.Y.; Xue, Z.H.; Liu, J.W.; Zhao, K.Y.; Bao, X.C. Effect of Alkali Treatment on Relaxation Properties of Wood. J. Northwest For. Univ. 2018, 33, 193-197.

27. Zhao, M.X.; Kang, L.; Chu, D.M.; Mu, J. Impact of ultrasonic/high temperature heat treatment on acoustics performance of Chinese zitherinstruments plates. Wood Process. Mach. 2016, 27, 45-50.

28. Lv, J.X.; Bao, F.C.; Jiang, X.M.; Zhao, Y.K. Studies on the effect of three different treatments on wood permeability. Scientia Silvae Sinicae 2000, 36, 67-76.

29. Peng, X.R.; Zhang, Z.K. Influence of Plasma Treatment on Six Kinds of Wood Surface Wettability. Sci. Silvae Sin. 2018, 54, 90-98.

30. Jin, C.D.; Li, J.P.; Han, S.J.; Wang, J.; Yao, Q.F.; Sun, Q.F. Silver Mirror Reaction as an Approach to Construct a Durable, Robust Superhydrophobic Surface of Bamboo Timber with High Conductivity. J. Alloy. Compd. 2015, 635, 300-306. [CrossRef]

31. Li, X.; Pei, H.Z.; Zhang, G.L.; Huang, P. Current Status and Development Trend of Commonly Used Techniques for Preparing Infrared Absorption Coating on Copper Substrate. J. Mater. Prot. 2013, 5, 15.

32. Xue, X.M.; Nan, C.H. Comparison of FTIR Spectra in Seven Conifer Softwood Samples. J. Anhui Agric. Univ. 2016, 43, 88-93.

(C) 2020 by the authors. Licensee MDPI, Basel, Switzerland. This article is an open access article distributed under the terms and conditions of the Creative Commons Attribution (CC BY) license (http://creativecommons.org/licenses/by/4.0/). 